\title{
A LICENÇA COMPULSÓRIA DE PATENTES NO CASO DE EMERGÊNCIA NACIONAL OU INTERESSE PÚBLICO
}

\section{LA LICENCIA COMPULSORIA DE PATENTES EN EL CASO DE EMERGENCIA NACIONAL O INTERÉS PÚBLICO}

\section{THE COMPULSORY LICENSE OF PATENTS IN CASE OF NATIONAL EMERGENCY OR PUBLIC INTEREST}

\author{
Marina Zava de Faria $^{1}$; Mayron Morais Damasceno ${ }^{2}$.
}

Quem poderia patentiar o sol?

Jonas E. Salk, quando perguntado por que não patenteava sua vacina contra a poliomielite.

RECEBIBO 29/01/2019

APROVADO 30/01/2019

PUBLICADO 04/01/2019

Editor Responsável: Carla Caldas

Método de Avaliação: Double Blind Review

E-ISSN: 2316-8080

DOI: 10.16928

RESUMO

Este artigo tem como temática principal apresentar a existência da licença compulsória de patentes em caso de emergência nacional ou interesse público em conjunto com o princípio da função social das patentes. Nesses termos apresentaremos a existência, evolução, legislação e proteção jurídica das patentes, desde seus primórdios até sua vigência na sociedade brasileira. Posteriormente trataremos sobre sua comercialização diferenciando a licença voluntária da compulsória, de modo que ao final, possamos apontar meios e modos de o Poder Público materializar a licença compulsória.

\footnotetext{
${ }^{1}$ Advogada e Professora. Atuação com ênfase em Direito Empresarial. Doutoranda em Direito Comercial pela Pontifícia Universidade Católica de São Paulo (PUC-SP). Mestre em Direito, Relações Internacionais e Desenvolvimento pela Pontifícia Universidade Católica de Goiás (2014). Especialista em Direito Empresarial e Docência Universitária pelo Instituto Goiano de Direito Empresarial (2012). Especialista em Direito Processual Civil pela Universidade Cândido Mendes (2012). Graduada em Direito pela Pontifícia Universidade Católica de Goiás (2009). Advogada da MZ Advocacia Corporativa. Membro da Comissão de Direito Empresarial da OAB/GO (2013-2015; 2016-2018). Professora do curso de Direito da Pontifícia Universidade Católica de Goiás (PUC-GO), Escola Superior Associada de Goiânia (ESUP), Faculdades Alfa (FA), Professora de Pós Graduação da Pontifícia Universidade Católica de Goiás e IPOG. Professora de cursinhos para concurso e exame da OAB. Email: marinazava@mzadvocaciacorporativa.com.br. Brasil. Goiânia/GO.

${ }^{2}$ Advogado e Escritor. Bacharel em Direito, Graduado pela Pontifícia Universidade Católica de Goiás (PUC - GO) em 2016, durante a graduação atuou como monitor na instituição, principalmente auxiliando professores e na realização de palestras. Participou de Congressos, Seminários e debates acerca das ciências sociais e sua aplicabilidade. Pós-graduando no MBA em Direito Imobiliário, Negocio e Operações pela Dalmass com duração de 2017/2 a 2019/2. Membro da CAJ - Comissão da Advocacia Jovem e da CEIG - Comissão Especial de Gestão e Inovação da OAB/GO desde 2018. E-mail: mayronadv@gmail.com. Brasil. Goiânia/GO.
}

PIDCC, Aracaju/Se, Ano VIII, Volume 13 no 01, p.132 a 147 Fev/2019 | www.pidcc.com.br 
PALAVRAS-CHAVES: PROPRIEDADE INDUSTRIAL. PATENTES. COMERCIALIZAÇÃO. LICENÇA COMPULSÓRIA.

\title{
RESUMEN
}

Este artículo tiene como tema principal presentar la existencia de la licencia obligatoria de patentes en caso de emergencia nacional o interés público en conjunto con el principio de la función social de las patentes. En estos términos presentaremos la existencia, evolución, legislación y protección jurídica de las patentes, desde sus inicios hasta su vigencia en la sociedad brasileña. Posteriormente trataremos sobre su comercialización diferenciando la licencia voluntaria de la obligatoria, de modo que al final, podamos apuntar medios y modos de que el Poder Público materializar la licencia obligatoria.

\section{PALABRAS CLAVES: PROPIEDAD INDUSTRIAL. PATENTES.} COMERCIALIZACIÓN. LICENCIA COMPULSIVA.

\begin{abstract}
This article has as main theme to present the existence of compulsory license of patents in case of national emergency or public interest in conjunction with the principle of social function of patents. In these terms we will present the existence, evolution, legislation and legal protection of patents, from its beginnings to its validity in Brazilian society. Later we will discuss its commercialization differentiating the voluntary license from the compulsory one, so that in the end, we can point out ways and means of the Public Power to materialize the compulsory license.
\end{abstract}

KEY-WORDS: INDUSTRIAL PROPERTY. PATENTS. COMMERCIALIZATION. COMPULSORY LICENSE.

\section{INTRODUÇÃO.}

O presente artigo buscará em sua explanação apresentar a existência e o surgimento dos direitos de propriedade industrial, para, posteriormente, adentrar ao âmago de sua discussão, explicar e delinear quando as patentes podem ser compulsoriamente licenciadas frente à vigência de um interesse público ou pela constatação de uma emergência nacional.

Para tanto, faremos algumas sedimentações, de modo que primeiramente será feita uma análise sobre o instituto da Propriedade Industrial no Brasil, condensando essa temática trataremos acerca de sua evolução, sobre a vigência da legislação, além de apresentar um panorama sobre proteção, características e possibilidades de concessão da patente.

Abordaremos didaticamente a vigência dos Tratados Internacionais de que o Brasil fez parte, assinou e ratificou. Bem como, sobre a vigência, em âmbito Nacional, de 
A LICENÇA COMPULSÓRIA DE PATENTES NO CASO DE EMERGÊNCIA NACIONAL OU INTERESSE

PÚBLICO

E-ISSN 2316-8080

legislação específica, qual seja, a Lei 9.279, de 1996, comumente conhecida como Lei de Propriedade Industrial.

Desta feita passaremos a tratar acerca do surgimento e das considerações legais que possibilitem a formulação do requerimento de registro de uma patente junto ao órgão competente, o Instituto Nacional de Propriedade Industrial, igualmente, faremos uma rápida analise dos requisitos necessários para tanto: novidade, atividade inventiva, industriabilidade e desimpedimento.

Posteriormente, em um segundo momento, abordaremos a temática do licenciamento enquanto possibilidade de comercialização e lucratividade por parte do detentor daquele direito. Nesses termos, apresentaremos as características legais e requisitos que devem ser cumpridos para que o inventor possa ceder ou licenciar a sua patente, após, especificamente em relação à licença, faremos um pequeno paralelo entre a licença voluntária e a licença compulsaria.

Ao final deste trabalho buscaremos apresentar especificamente acerca da modalidade de licença compulsória que ganha vigência frente à constatação de um interesse público ou com a necessidade de segurança nacional, para tanto abordaremos o ato praticado pelo Poder Público e sua conjunção com o princípio da função social da patente.

Em deslinde, esta pesquisa que contém caráter bibliográfico, foi realizada e consubstanciada com base em dados obtidos em investigação junto de diversos livros, doutrinas, revistas, jornais e artigos a respeito do tema que é recente e tem gerado vultosa polêmica.

\section{EVOLUÇÃO E PROTEÇÃO JURÍDICA DAS PATENTES.}

\section{1 - HISTÓRICO.}

O saber sempre ocupou lugar de destaque na história da humanidade. A criatividade do ser humano, ao longo de sua existência na terra, propiciou o desenvolvimento da sociedade. Entretanto, durante muito tempo, o homem não teve a preocupação em proteger os seus inventos.

Segundo registros históricos, o primeiro caso de proteção concedida a um invento se deu em 1236, quando na cidade de Bordeaux, na França, concedeu-se a "Banafasus de Sancta e Companhia" o direito de explorar com exclusividade, por 15 (quinze) anos, o 
método flamengo de tecer e tingir tecidos de lã. Ressalta-se, ainda, como um marco importante na história da propriedade industrial, o fato de, o genial Leonardo da Vinci, utilizar artifícios, como a prática de escrever ao contrário ou de deixar erros propositais em seus textos, para proteger os seus inúmeros inventos.

No cenário historio podemos destacar, ainda, o surgimento das codificações de patentes editadas em Veneza em 1474 e na Inglaterra em 1623, esta chamada de "statue of monopolies". Ambos os documentos já traziam a ideia de "novidade e aplicação industrial" para a caracterização de uma invenção. Ideias, que, fazem até hoje parte do direito de propriedade industrial.

Apesar de alguns episódios de proteção dos inventos, foi mesmo, somente após a Revolução Industrial que se percebeu a importância de conferir proteção aos direitos de propriedade industrial. Com um aumento significativo no número de inventos, percebeu-se que era necessário proteger os direitos do inventor.

Com muita maestria, narra sobre os inventos no período da Revolução Industrial, o historiador Eric Hobsbawm em seu livro a Era das Revoluções:

\begin{abstract}
Nas Revoluções Industriais dos séculos XVIII e XIX ocorreu a ampliação da substituição da energia humana e animal pela inanimada, com eficiência multiplicada; a aceleração da troca da capacidade humana por instrumentos mecânicos; e a descoberta e/ou melhoria de métodos de obtenção e elaboração de matérias primas. Vários fatores atuaram incentivando as inovações. Por exemplo, a importação de tecidos da Índia e da China pela Inglaterra demonstrou uma influência do comércio sobre o desenvolvimento da indústria no último país, principalmente a partir do momento em que houve reserva de mercado e substituição de importações. Ao mesmo tempo, um importante mercado interno, com uma relativamente grande urbanização e mercantilização, estimulou a produção de bens de consumo de massa (como têxteis) na Inglaterra. Por outro lado, as mudanças que ocorriam foram induzindo, pelo aparecimento de necessidades práticas, novas inovações. Em 1765 houve a invenção de uma máquina chamada "spinning-jenny", e em 1767 de outra chamada "water-frame" (datas prováveis), o que permitiu um grande avanço da fiação, com mais rapidez e qualidade. A "water-frame" foi aplicada em fábricas, utilizando energia hidráulica. Com isto a técnica passou a ter um caráter econômico, provocando um grande aumento de produtividade e queda de preços (Mantoux, 1928, p. 206-10). Houve também, neste período, outros desenvolvimentos, como a invenção da estamparia (que antes era feita manualmente) e progressos na química, com processos de branqueamento e tintura. Inovações revolucionárias ocorreram também na indústria do ferro. Usava-se carvão de madeira para a elaboração do metal, o que tendia a gerar falta deste combustível dada a tendência à extinção das matas.
\end{abstract}

A onerosidade da pesquisa e o desenvolvimento de tecnologia, somada a percepção de sua importância como fator determinante para a diferenciação dos povos foi alguns dos motivos que levaram os Estados Nacionais a pensarem a respeito de medidas que estimulassem e protegessem os resultados do processo criativo. 
Nesse cenário foi realizado, em 1883, a primeira Convenção de Paris, com a finalidade de tentar harmonizar e uniformizar o sistema internacional de proteção à propriedade industrial, contanto, inclusive, com a participação do Brasil. Em seu artigo $1^{\circ}$ a Convenção previa:

Art. $1^{\circ}$ "a proteção da propriedade industrial tem por objeto as patentes de invenção, os modelos de utilidade, os desenhos ou modelos industriais, as marcas de fábrica ou de comércio, as marca de serviço, o nome comercial e as indicações de proveniência ou denominações de origem, bem como a repressão da concorrência desleal"

O Brasil sempre esteve presente no cenário de discussão de direito da propriedade industrial, tendo sido inclusive considerado como um país pioneiro a proteção destes direitos. Um exemplo disto, é que, ao longo da história, quase todas as Constituições Brasileiras cuidaram do direito da propriedade industrial, e, ainda, a sua participação em tratados e convenções de proteção a esses direitos.

\section{2 - LEGISLAÇÃO, TRATADOS E ACORDOS INTERNACIONAIS.}

Com exceção da Constituição de 1937, todas as Constituições Brasileiras trouxeram positivado o direito sobre as criações e os inventos industriais, deixando clara a importância dada pelo Estado Brasileiro à proteção da propriedade industrial.

A Constituição de 1824 previa em seu artigo 179, inciso XXVI, que "Os inventores terão propriedade de suas descobertas ou das produções. A lei lhes assegurará um privilégio exclusivo e temporário ou lhes remunerará em ressarcimento da perda que hajam de sofrer pela vulgarização."

A Constituição Federal de 1891, por sua vez, tratou do assunto, em seu artigo 72, § 25 dispondo que os inventos industriais pertenceriam aos autores, aos quais ficaria garantido por lei um privilégio temporário ou seria concedido pelo Congresso um prêmio razoável quando houvesse conveniência em vulgarizar o invento.

A Constituição de 1934 praticamente não alterou a redação do texto constitucional anterior, conforme expressa o art. 113, item 18: “Os inventos industriais pertencerão aos seus autores, aos quais, a lei garantirá privilégio temporário ou concederá prêmio justo, quando a sua vulgarização convenha à coletividade"

Como já citado, a Constituição de 1937, infelizmente não trouxe nenhuma referência expressa aos direitos da propriedade industrial. 
A Constituição de 1946, por sua vez, voltou a dispor de forma expressa sobre as criações e os inventos industriais, fazendo-o no seu art. 141 § 17. A Constituição de 1967 também cuidou da matéria em seu art. 150 § 24, dispondo que "a lei garantirá aos autores de inventos industriais privilégio temporário para sua utilização e assegurará a propriedade das marcas de indústria e comércio, bem como a exclusividade do nome comercial."

Por fim, a Constituição Federal de 1988 cuida dos direitos da propriedade industrial na parte dos direitos e garantias individuais, estabelecendo em seu art. $5 .^{\circ}$, inciso XXIX o seguinte:

\footnotetext{
A lei assegurara aos autores dos inventos industriais privilégio temporário para sua utilização, bem como proteção às criações industriais, à propriedade das marcas, aos nomes de empresas e a outros signos distintivos, tendo em vista o interesse social e o desenvolvimento tecnológico e econômico do País.
}

Como determinado pela Constituição Federal, entrou em vigor em 1996 a Lei 9.279, conhecida como Lei de Propriedade Industrial (LPI), que regula, atualmente, os direitos e obrigações relativos a propriedade industrial no Brasil, estabelecendo em seu art. $2^{\circ}$ que "a proteção dos direitos relativos à propriedade industrial, considerado o seu interesse social e o desenvolvimento tecnológico do País, efetua-se mediante: I- concessão de patentes de invenção e de modelo de utilidade; II- concessão de registro de desenho industrial; III concessão de registro de marcas; IV - repressão às falsas indicações geográfica; e V repressão à concorrência desleal."

Destaca-se, ainda, que o Brasil é signatário do Acordo TRIPS, Tratado Internacional integrante de um conjunto de acordos assinados em 1994 que deu origem, inclusive, à Organização Mundial do Comércio (OMC). O Brasil ratificou o Acordo Trips por meio do decreto legislativo 30/1994 e o promulgou pelo decreto presidencial 1.355/1994. O referido acordo tem como objetivo reduzir distorções e obstáculos ao comércio internacional e levando em consideração a necessidade de promover uma proteção eficaz e adequada dos direitos de propriedade intelectual.

Conforme, a Lei de Propriedade Industrial e a Constituição Federal Brasileira, os bens protegidos pelo direito da propriedade industrial são, portanto, quatro: a invenção e o modelo de utilidade, protegidos pela concessão de patente, e a marca e o desenho industrial, protegidos mediante a concessão de registro, e ainda, a repressão das falsas indicações geográficas e a concorrência desleal.

Como objeto deste trabalho, iremos nos restringir a estudar a invenção protegida por meio de patente, as suas peculiaridades, limitações, e possibilidades de licenciamento. 


\title{
1.3 - CONCEITO E CARACTERÍSTICAS.
}

Muito se discute a respeito do conceito de invenção. A Lei de Propriedade Industrial não definiu o que vem a ser uma invenção. Muitos autores alegam que a lei deixou de definir o tema invenção, por se tratar, ao mesmo tempo, de um conceito difícil de ser definido e de uma noção facilmente assimilada por qualquer pessoa. Sobre o assunto trata o doutrinador Fábio Ulhoa Coelho (2014, p.234) da seguinte forma:

\begin{abstract}
Dos quatro bens industriais, a invenção é a única não definida pela lei. Esta ausência de definição corresponde à tradição legislativa sobre a matéria, nacional e estrangeira, e é plenamente justificável pela extrema dificuldade de se conceituar o instituto. Todos de fato, sabem intuitivamente o que é uma invenção e não há dúvidas quanto aos elementos essenciais que a caracterizam (criação original do espírito humano, ampliação ao domínio que o homem exerce sobre a natureza etc.), mas não é fácil estabelecer os seus exatos contornos conceituais.
\end{abstract}

Sobre o significado da palavra "INVENTAR", dispõe o dicionário Aurélio:

Ação de inventar, de criar algo de novo. Coisa inventada: uma feliz invenção. Descoberta, sobretudo falando-se de certas relíquias. Ação de achar argumentos, ideias e meios para convencer e persuadir.

O que se percebe é que em razão da dificuldade em definir invenção, o legislador preferiu se valer de um critério de exclusão, apresentando uma lista de manifestações do intelecto humano que não são consideradas como invenções, dispostas no art. 10 da Lei 9.279 de 1996. Dispões o artigo que não são consideradas invenções: I- as descobertas, teorias científicas e métodos matemáticos; II - concepções meramente abstratas; III - esquemas, planos, princípios ou métodos comerciais, contábeis, financeiros, educativos, publicitários, de sorteio e de fiscalização; IV - obras literárias, arquitetônicas, artísticas e científicas ou qualquer criação estética; V - programas de computador em si; VI - apresentação de informações; VII - regras de jogos; VIII - técnicas e métodos operatórios ou cirúgicos, bem como métodos terapêuticos ou de diagnóstico, para aplicação no corpo humano ou animal; IX - o todo ou parte de seres vivos naturais e materiais biologicamente encontrados na natureza, ou ainda que dela isolados, inclusive o genoma ou germoplasma de qualquer ser vivo natural e os processos biológicos naturais.

Podemos considerar então que Invento é "uma solução técnica original de um problema técnico”. Essa a noção que deriva do texto constitucional. Invenção é a criação 
industrial maior, objeto da patente de invenção, à qual, tradicionalmente, se concede prazo maior e mais amplidão de proteção (BARBOSA, 2014).

Nessa esteira dispõe o artigo $8^{\circ}$ da LPI que: "é patenteável a invenção que atenda todos os requisitos de novidade, atividade inventiva e aplicação industrial”.

Do dispositivo decorre a interpretação de que para que seja concedida a patente de invenção é necessário ter o objeto as seguintes características: natureza inventiva, apresentar novidade e aplicação industrial. Seguem os requisitos:

a) Novidade.

O requisito da novidade se considera preenchido quando a invenção não está compreendida no estado de técnica. Um determinado invento atenderá o requisito da novidade se constituir algo desconhecido até mesmo para a comunidade científica especializada na respectiva área de conhecimento.

Desta forma, para que um determinado invento seja considerado novo, faz necessário que a invenção seja diferente de tudo que, até aquele momento, era de conhecimento do púbico

A respeito do tema, decidiu a $2^{\mathrm{a}}$ Turma Especializada do TRF - $2^{\mathrm{a}}$ Região na Apelação Cível No416314:

PROPRIEDADE INDUSTRIAL. PATENTE. INVENÇÃO. NOVIDADE.
ESTADO DA TÉCNICA. DISPOSITIVO DE ESTRATIFICAÇÃO DE
CONVECÇÃO TÉRMICA. APERFEIÇOAMENTOS. 1. A patente protege a
invenção que apresente, em relação ao estado da técnica, uma novidade absoluta, em
outras palavras, a invenção deve ser diferente de TUDO o que, até aquele momento,
era de conhecimento do público. 2. Determinadas situações apresentam problemas
técnicos que o inventor procura solucionar com sua invenção, em nítida relação de
causa e efeito. Assim, a invenção é, cada vez mais, um novo meio ou uma nova
aplicação de meios já conhecios, com o fim de melhorar a invenção dos outros. 3 .
No caso concreto ora em análise, as novas dimensões da peça e as melhorias
implementadas na proteção das tubulações, no que se refere à transmissão de calor,
agregaram mais funcionalidade ao conjunto, conferindo-lhe caráter de novidade
suficiente a fundamentar a concessão do privilégio. Apelação desprovidas. DJU -
Data: $08 / 07 / 2008$ (grifo nosso)

b) Atividade Inventiva.

O segundo requisito para a concessão da patente é a "atividade inventiva". Dispõe a Lei de Propriedade Industrial que a invenção é dotada de atividade inventiva sempre que, para um técnico no assunto, não decorra de maneira evidente ou óbvia do estado da 
técnica (Art. 13 da LPI).

Para ser patenteável a invenção, não pode ser derivada de forma simples dos conhecimentos nele reunidos. É necessário que a invenção resulte de um verdadeiro engenho, de um de criação intelectual.

Segundo Campinho (2015, p.354), “o inventor deverá demonstrar que chegou àquele resultado novo em decorrência específica de um ato de criação seu." Dispõe, ainda, que serve esse requisito, enfim, para distinguir a invenção de uma mera descoberta, de modo que o direito da propriedade protege o inventor, mas não o mero descobrir." "Como exemplo que diferencia o descobridor do inventor, podemos citar a energia elétrica. Quem descobriu a energia elétrica não tem direito de propriedade industrial, uma vez que tal descoberta não tem natureza inventiva, já quem inventou a lâmpada será protegido pelos direitos da propriedade industrial, pela característica inventiva na lâmpada."

Foi nos Estados Unidos o local em que se desenvolveu o requisito da atividade inventiva, lá denominado de "Non Obviousness", tendo sido incorporado pelo direito de propriedade industrial brasileiro somente a partir da entrada em vigor da LPI em 1996.

c) Industriabilidade.

É necessário que o invento criado seja útil e factível. Se alguma pessoa cria algo novo, contudo, não é possível que este seja produzido em larga escala, não é possível que o objeto seja patenteado. Muitas vezes, ocorre determinada situação em que misturando elementos se descobre algo, todavia, sem saber ao certo quais foram os elementos, a sua quantidade, ordem, características, é impossível a sua reprodução industrial.

Dispõe o art. 15 da LPI que: "a invenção e o modelo de utilidade são considerados suscetíveis de aplicação industrial quando possam sem utilizados ou produzidos em qualquer tipo de indústria".

Desta forma, se alguém cria algo novo, mas que não pode ser produzido industrialmente, ou seja, que não poder ser objeto de aplicação industrial, a respectiva criação não poderá ser patenteada.

d) Desimpedimento.

O último requisito da patenteabilidade é o desimpedimento. Existem invenções PIDCC, Aracaju/Se, Ano VIII, Volume 13 no 01, p.132 a 147 Fev/2019 | www.pidcc.com.br 
que, embora novas, inventivas e industrializáveis, não podem receber a proteção da patente por razões de ordem pública.

Encontra-se no art. 18 da LPI os impedimentos existentes no direito brasileiro, atualmente: a) as invenções contrárias a moral, aos bons costumes e à segurança, à ordem e à saúde pública; b) substâncias, matérias, misturar, elementos ou produtos resultante de transformação do núcleo atômico, bem como a modificação de suas propriedades e os processos respectivos; c) seres vivos ou parte deles.

Desta, forma, sendo o invento dotado das características: novidade, natureza inventiva, aplicação industrial, e estando livre dos impedimentos previstos pela Lei de Propriedade Industrial, poderá, ser patenteado.

\section{4 - PEDIDO E PROTEÇÃO DE PATENTE.}

A concessão de uma patente de invenção não é um ato simples, obtido automaticamente após o requerimento do inventor. $\mathrm{O}$ ato de concessão da carta patente é precedido de um procedimento administrativo burocrático e muitas vezes lento.

O pedido de proteção será feito junto ao INPI pelo autor da invenção. O Instituto Nacional de Propriedade Industrial é uma autarquia federal brasileira, criada em 1970, vinculada ao Ministério do Desenvolvimento, Indústria e Comércio Exterior, que tem por finalidade, segundo a Lei 9.279/96, executar, no âmbito nacional, as normas que regulam a propriedade industrial, tendo em vista sua função social, jurídica, econômica e técnica.

O INPI é o orgão responsável pelo registro e concessão de marcas, patentes, desenho industrial, transferência de tecnologia, indicação geográfica, programa de computador e Topografia de Circuito Integrado.

Superados todos os trâmites legais, uma vez deferido o pedido, a patente será concedida, expedindo-se a respectiva carta-patente nos termos do artigo 38 da Lei de Propriedade Industrial.

Importante ressaltar que a patente é um privilégio concedido ao inventor e não dura para sempre. A proteção conferida é temporária, e os prazos previsto em nossa atual legislação seguem as disposições do Acordo Trips.

Segundo o artigo 40 da LPI, "a patente de invenção vigorará pelo prazo de 20 (vinte) anos contados da data do depósito". Protegidos pela patente devidamente concedida pelo INPI, nos termos das reivindicações, do relatório descritivo e dos desenhos apresentados 
quando da realização do pedido, o seu titular terá o direito de exploração econômica exclusiva do invento patenteado podendo "impedir terceiro, sem o seu consentimento, de produzir, usar, colocar à venda, vender ou importar com estes propósitos: I- produto objeto de patente; II processo ou produto obtido diretamente por processo patenteado".

O titular de uma patente, como o dono de um apartamento, tem meios legais de impedir o uso do objeto de seu direito por qualquer pessoa não autorizada: ninguém pode invadir o imóvel, ou explorar uma tecnologia patenteada, sem dar conta de seus atos segundo o que a lei dispõe. Isto é o mesmo que dizer que os direitos decorrentes de uma patente, como os resultantes da propriedade dos bens materiais, se exercem, indistintamente, contra todas as pessoas: e a ninguém é facultado esbulhar apartamentos ou violar patentes. (BARBOSA, 2015).

\section{A CONCESSÃo de USO dA PATENTE de INVENÇÃo POR MEIO DA LICENÇA.}

Dentro de tudo que foi apresentado, bem como, do fato de que as patentes de invenções são objetos criados por uma pessoa, percebe-se sua disponibilidade, ou seja, são direitos disponíveis e, portanto, comercializáveis. Logo, o empresário detentor da cartapatente ou do pedido de patente tem condições de licenciar esse direito (RAMOS; GUTERRES, 2016).

A exploração do direito industrial se realiza direta ou indiretamente. Na primeira forma, o próprio titular da patente ou do registro assume os riscos da atividade empresarial, fabricando e comercializando ele mesmo objeto inventado. A forma indireta de exploração do direito industrial decorre da outorga de licença de uso, pelo titular da patente ou do registro em favor de um empresário.

Portanto, a licença é precisamente uma autorização, dada por quem tem o direito sobre a patente, para que uma pessoa faça uso do objeto do privilégio. Sendo a patente licenciada o titular da patente promete não empregar os seus poderes legais para proibir a pessoa autorizada do uso do objeto da patente e, ainda, dá ao licenciado o direito de explorar o objeto da patente, com todos os poderes, instrumentos e meios que disto decorram.

Em linhas gerais a legislação criou a licença voluntária (arts. 61 a 67 da LPI) e a licença compulsória (arts. 68 a 74 da LPI), ou seja, uma feita pelo próprio detentor do direito industrial que criou, produziu e registrou o invento e o outro, licença compulsória, para os 
casos em que se verificar o enquadramento legal para sua devida concessão.

Normalmente a licença é um ato voluntário, um acordo amplamente negociado entre o licenciador e o licenciado, para tanto a legislação o como licença voluntária, uma vez que está em conformidade com o desejo e a vontade do detento dos direitos de determinada patente de invenção.

Dentro dessa possibilidade e de seu interesse a legislação aponta obrigação de averbação do contrato de licenciamento voluntário junto ao INPI para que o mesmo venha a produzir seus efeitos contra terceiros, resguardando, nesses temos os direitos tanto do licenciado quanto do licenciador que utiliza daquele invento para o exercício de sua atividade empresária.

Importante apontar que já possibilidade de o titular da patente requer que o próprio INPI faça uma oferta para a licença de sua patente, tal possibilidade é ventilada pela própria legislação nos artigos 64 a 67 da LPI, portanto, é preciso que o titular do direito siga todos os tramite apresentados cabendo ao INPI auxiliá-lo na publicidade da oferta para fins de exploração.

Em contrapartida, a legislação prevê hipóteses em que o titular da patente é obrigado, pelo INPI, por determinação administrativa ou mesmo judicial, a licenciar o seu uso em favor de terceiros interessados, trata-se da denominada Licença Compulsória.

Analisando os dispositivos legais, percebe-se que a licença compulsória será determinada, em alguns casos, como forma de sancionar o titular da patente, e, em outros casos, como forma de atender aos imperativos de ordem pública. São as seguintes: a) exercício abusivo do direito; b) abuso do poder econômico ${ }^{3}$; c) falta de exploração integral do invento; d) comercialização insatisfatória para atendimento das necessidades do mercado; e) dependência de uma patente em relação a outra; f) emergência nacional ou interesse público, declarado por ato do Poder Executivo Federal.

Nos casos descritos, nas letras "a", "b", "c" e "d", chamados pela doutrina de licença por abuso de direitos ou licença por abuso de direito econômico, resta evidente que a licença compulsória da patente decorre de condutas do próprio titular da patente que não são compatíveis com os princípios que justificam a concessão de um privilégio legal que assegura direito de exploração exclusiva do invento.

Assim, configurada uma dessas situações, poderá qualquer pessoa interessada requerer ao INPI a licença compulsória.

\footnotetext{
${ }^{3}$ Considera-se para tanto a prática de atos inflacionários que estão em desacordo com a ordem econômica, ou seja, aqueles atos que estão em desconformidade com a Lei 12.529, de 2011, comumente conhecida como Lei Antitruste. 


\section{O LICENCIAMENTO COMPULSÓRIO POR EMERGÊNCIA NACIONAL OU INTERESSE PÚBLICO.}

$\mathrm{O}$ ato inventivo protegido pela patente busca seu respaldo junto à consagração do princípio da função social da patente, o qual pode ser seccionado em duas subdivisões, primeiro, pois a concessão não é simplesmente algo privado com o fito de proteger e permitir a consagração do lucro, a finalidade legislativa é a de trazer ao público a existência dos atos registrados com o intuito de incentivar a criação de novas invenções, seja por centros de pesquisa ou outros empresários; em segundo, para quando verificar necessário proteger a coletividade em detrimento do privado se valendo, assim, do interesse público ou da emergência nacional.

$\mathrm{Na}$ primeira subdivisão do princípio a patente de invenção é cedida para o empresário no intuito de permitir sua proteção de uso, bem como para que possibilite seu conhecimento e sua visibilidade no mundo científico, outras pessoas não podem utilizá-la sem a devida licença, contudo, podem servir se desse conhecimento para inovar e criar novas invenções por meio de uma já existente. Desse modo, é visível que uma das funções da patente é propagar, aumentar e incentivar as criações e os inventos, fazendo com que os empresários tragam a público tais atos e possam fomentar o desenvolvimento.

Em seu segundo ponto, a legislação buscou ainda melhorar e aperfeiçoar a qualidade de vida social e pública, uma vez que a invenção possa ser utilizada em benefício social que venham em auxílio e defesa de toda a coletividade, frente o interesse público ou uma emergência nacional, atendendo, portanto, ao beneplácito da supremacia do coletivo sobre o privado, tanto foi que a própria legislação consagrou a existência da licença compulsória.

A art. 71 da Lei de Propriedade Industrial traz, também, uma hipótese importantíssima de licença compulsória, chamada de licença por interesse público.

De acordo com esse dispositivo, "nos casos de emergência nacional ou interesse público, declarados em ato do Poder Executivo Federal, poderá ser concedida, de ofício, licença compulsória, temporária e não exclusiva, para a exploração da patente, sem prejuízo dos direitos do respectivo titular."

O licenciamento compulsório lastreada no art. 71 da LIP, é a autorização outorgada pelo Estado para que terceiros possam explorar a patente sem o consentimento do 
titular, desde que atendidos os requisitos legais. Este tipo de licença não atende a interesses privados de interessados, mas aos imperativos de ordem pública. Ademais, nesse caso cabe ao Chefe do Poder Executivo Federal, ou seja, ao Presidente da República tomas a decisão de ofício. Seja qual for o fundamento legal da licença compulsória, elas serão sempre concedidas mediante remuneração e sem exclusividade.

Como exemplo prático dessa modalidade de licença, bem como sua importância em nível nacional, podemos citar o que veio a ser comumente chamado "quebra de patentes". No caso, o Poder Público, por ato do Presidente da República (Decreto nº 6.108/2007), realizou a licença compulsória do medicamento "Efavirenz", uma vez que seu uso no combate ao vírus da AIDS acaba sendo de grande repercussão nacional e afeta o interesse público, por meio deste decreto o mencionado medicamento passou a ter fins de uso público não comercial (RAMOS, 2011).

Percebe-se, portanto que a iniciativa dessa modalidade de licença compulsória por ato de interesse público ou segurança nacional foi instituída justamente frente à conflagração do confronto do público com o privado, ou seja, frente à necessidade de proteger e manter a dignidade da pessoa humana é preciso que o governo faça uma intervenção, vez que seu papel é cuidar, governar e guardar os seus.

Ocorre, todavia, que não cabe ao governo assumir uma criação como se sua fosse, sendo necessário, quando se vislumbrar a necessidade de tal licenciamento o resguardo aos direitos do inventor e proprietário do bem em questão, cabendo devida fiscalização para que o governo não tome para si os direitos e a propriedade da invenção e sua criação.

Entendemos ainda que o Governo deve ser claro em sua atuação e repassar todas as informações acerca de custas e gastos para o dono do ato inventivo, permitindo que ele tenha total conhecimento do uso de sua patente, ainda que seja de interesse público seu uso é temporário, de modo que ao final do praz estipulado deverá sua proteção e uso integral voltar à posse do inventor.

\section{CONCLUSÃO.}

Podemos confabular que o presente artigo é de suma importância para demonstrar a existência do que é a patente e de como funciona o seu requerimento e proteção jurídica junto ao órgão competente, o INPI, junto ao qual o empresário poderá apresentar seu pedido e comercializar seu invento recebendo, contrapartida, os royalties advindos dessa negociação. 
Demonstramos ainda que apesar do empresário poder se valer da comercialização por meio da licença voluntária de sua patente ele também pode vir a ser impedido de realizar sua comercialização, de modo temporário, por ato executado pelo Chefe do Poder Executivo, denominado licença compulsória por interesse público ou segurança nacional.

Esse fato se vislumbra frente a importância de determinada patente ser utilizada para combater enfermidades, principalmente, quando os gastos para aquisição daquele medicamento ultrapassam a capacidade econômica de muitas famílias que gravitam na zona de pobreza e até mesmo de países pouco desenvolvidos que não detém nenhum recurso econômico para adquirir quantidade necessária de algum medicamento, portanto, verifica-se que tais atos vão em conformidade com o princípio da função social da patente.

O licenciamento compulsório serve - e se só para isso fosse, já seria suficientemente válido - para lembrar a todo momento, os fins para os quais outro importante instrumento, chamada patente, foi colimado. Acima todos os interesses particulares, deverá ser analisado, sempre, a função social do instituto da patente.

A existência de um sistema normativo que assegure o direito de patente de forma eficiente é fundamental para o desenvolvimento tecnológico, especialmente em setores de alta relevância social como o farmacêutico. Por outro lado, também é de grande importância a existência de um mecanismo como o licenciamento compulsório, que permite que a patente exerça sua função social, sua função pública.

Entretanto, ressaltamos a importância de limitação das hipóteses em que o licenciamento compulsório de um medicamento pode ser realizado como fator essencial para evitar a utilização deste instituto de forma indiscriminada, bem como, para evitar que os empresários mantenham "sob sigilo" os seus inventos frente o temor de perder seu fator lucro. 


\section{REFERÊNCIAS.}

ABPI, 2007. Licença Compulsória. Fatos e mitos. Boletim da ABPI. Maio, 2007. n. 85. Disponível em: < http://www.abpi.org.br/pdfs/boletim/Bol85.pdf $>$. Acesso em: 25 de ago de 2011.

BARBOSA, Denis Borges. Propriedade intelectual. Disponível em: $<$ www.denisbarbosa.addr.com/ibmec4.rtf>. Acesso em: 13 jun.2011

. Propriedade intelectual: a aplicação do acordo TRIPs. 2. ed. Rio de Janeiro: Lumen Juris, 2005.

BARROS, Carla Eugenia Caldas. Manual de Direito da Propriedade Intelectual, Evocati: Aracaju, 2007.

2004

. Aperfeiçoamento e Dependência em Patentes, Lumen Juris: Rio de Janeiro,

BRASIL, 1971. Lei 5.772 de 21.12.1971. Institui o Código da Propriedade Industrial e dá outras providências. Disponível em: $<$ http://www.inpi.gov.br/menuesquerdo/patente/pasta_legislacao/lei_5772_1971_html $>$.

Acesso em: 20 jan. 2018.

Disponível

1998. Constituição. Constituição da República Federativa do Brasil de 1988.

$<$ http://www.planalto.gov.br/ccivil_03/constituicao/constituicaocompilado.htm>. Acesso em 27 fev 2018. (É da internet?? não constava link nem acesso acrescentei).

1996. Lei 9.279 de 14 de maio de 1996. Regula direitos e obrigações relativos à

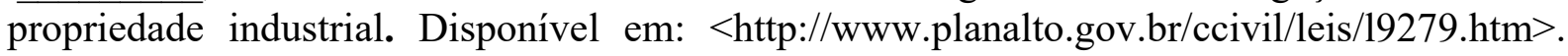
Acesso em: 20 jan. 2018.

CAMPINHO, Sergio. Direito de Empresa, O: À Luz do Novo Código Civil. $11^{\mathrm{a}}$ ed. Renovar, 2011.

COELHO, Fabio Ulhoa. Curso de Direito Empresarial. 15ª ed. São Paulo. Saraiva, 2011. V.I.

DWORKIN, Ronald. O Império do Direito. $2^{\mathrm{a}}$ ed. São Paulo. Martins Editora, 2007.

RAMOS, André Luiz Santa Cruz. Direito Empresarial Esquematizado $1^{\text {a }}$ ed. São Paulo. Metódo, 2011. V. I.

; GUTERRES, Thiago Martins. Lei de Propriedade Industrial Comentada: Lei 9.279, de 14 de maio de 1996. Salvador. Ed. JusPodivm, 2016.

Revisa Veja < http://veja.abril.com.br/blog/reinaldo/geral/veja-3-por-que-quebra-patente-foium-pessimo-negocio-para-brasil/http://www.aids.gov.br/ > Acesso em: 22 de abril de 2012.

SEVERINO, Antonio Joaquim. Metodologia do Trabalho Científico. 24a ed. São Paulo. Cortez, 2006. 